\title{
Educação Ambiental e Iniciação Científica no Ensino Fundamental
}

\author{
Anarisa Fátima Carminatti* \\ * Mestranda no Mestrado Profissional em Engenharia e Ciências Ambientais, Centro de Ciências \\ Exatas e Tecnologia, Universidade de Caxias do Sul, Brasil. \\ E-mail: anarisacarminatti@hotmail.com. \\ Vania Elisabete Schneider \\ •Diretora do Instituto de Saneamento Ambiental, Centro de Ciências Exatas e Tecnologia, \\ Universidade de Caxias do Sul, Brasil. \\ E-mail: vescnei@ucs.br.
}

\begin{abstract}
Resumo
O desenvolvimento de habilidades científicas é o principal objetivo da Alfabetização Científica e Tecnológica, alvo de interesse de inúmeros pesquisadores que tentam tanto elucidar os mecanismos de concretização junto aos estudantes, quanto avaliar os indicadores desse processo. Neste estudo, objetivou-se avaliar a efetividade da Educação Ambiental para o desenvolvimento de habilidades científicas em estudantes de uma escola pública, localizada na Microbacia do Arroio Pena Branca no Município de Caxias do Sul - RS, utilizando como tema motivador os recursos hídricos. A metodologia qualitativa participante foi a escolhida e, como estratégias para coleta de dados, utilizou-se o questionário e o grupo focal. O método de aprendizagem ativa utilizado com os participantes foi o Ensino pela Pesquisa. O envolvimento dos estudantes de Ensino Fundamental nas atividades de pesquisa demonstrou-se uma importante ferramenta para a compreensão das metodologias científicas e sua aplicabilidade em atividades de Educação Ambiental, bem como para a formação profissional futura, incluindo Engenharia Ambiental.
\end{abstract}

Palavras-chave: Educação Ambiental, Iniciação Científica, Recursos Hídricos.

\begin{abstract}
The development of scientific skills is the main goal of the Scientific and Technological Literacy, which has been currently target of interest of many researchers who try to elucidate the mechanisms
\end{abstract}


of implementation with the students, and to evaluate the indicators of this process. This study aimed to evaluate the effectiveness of environmental education to the development of scientific skills in students of a public school, located on the watershed called Arroio Pena Branca in the city of Caxias do Sul, in the State of Rio Grande do Sul, Brazil. The qualitative methodology participant was chosen and, as strategies for data collection, we used the questionnaire and focus group. The active learning method used with participants was teaching by research. The Elementary school students' involvement in research activities proved to be an important tool for the understanding of scientific methodologies and their applicability in environmental education activities, as well as to vocational training.

Keywords: Environmental Education, Scientific Research, Water Resources.

\section{Resumen}

El desarrollo de habilidades científicas es el objetivo principal de la Alfabetización Científica y Tecnológica, punto de interés de innúmeros investigadores que intentan no sólo descubrir los mecanismos de concretización junto a los estudiantes, sino también evaluar los indicadores de este proceso. El objetivo de este estudio fue evaluar la efectividad de la Educación Ambiental para el desarrollo de habilidades científicas de estudiantes de una escuela pública, ubicada en la Microbacia del Arroyo Pena Branca en el municipio de Caxias do Sul - RS, usando como tema de motivación los recursos hídricos. Fue escogida la metodología cualitativa participante y, como estrategias de colecta de datos, se utilizó un cuestionario y el grupo focal. El método de aprendizaje activo utilizado con los participantes fue la Enseñanza por la Investigación. La participación de los estudiantes de Educación Fundamental en las actividades de investigación demostró ser una herramienta importante para la comprensión de las metodologías científicas y su aplicación en actividades de Educación Ambiental, así como para la futura formación profesional, incluyendo Ingeniería Ambiental.

Palabras claves: Educación Ambiental, Iniciación Científica, Recursos Hídricos. 


\section{Introdução}

A faixa etária jovem apresenta o potencial ideal para a construção de novos conceitos de ocupação do espaço geográfico e a formação de uma consciência crítica em torno de questões e problemas ambientais ${ }^{1}$. O desenvolvimento de habilidades científicas seria a meta principal da Alfabetização Científica e Tecnológica e que atualmente é alvo de interesse de inúmeros pesquisadores que tentam tanto elucidar os mecanismos de concretização junto aos estudantes, quanto avaliar os indicadores desse processo, verificando com clareza os avanços adquiridos pelos mesmos. Para o desenvolvimento de tais habilidades nos participantes da pesquisa, o assunto recursos hídricos foi o motivador, uma vez que consiste em um dos elementos naturais há muito impactado pelas atividades humanas. No Brasil estas questões vêm sendo amplamente discutidas nos diversos segmentos da Sociedade, embora ações mais efetivas que conduzam à convivência harmônica do homem com a natureza, ainda sejam insuficientes ${ }^{2}$.

A Política Nacional de Educação Ambiental, Lei n ${ }^{\circ}$ 9.795/1999, apresenta a Educação Ambiental como tema transversal, envolvendo os processos por meio dos quais o indivíduo e a coletividade constroem valores sociais, conhecimentos, habilidades, atitudes e competências voltadas para a conservação do meio ambiente, considerando-a um componente essencial e permanente da educação nacional, devendo estar presente, de forma articulada, em todos os níveis e modalidades do processo educativo, em caráter formal e não formal ${ }^{3}$. Estes referenciais tornam-se essenciais quando do estabelecimento de metas a serem atingidas a médio e longo prazo nas questões ambientais, mas também da formação cidadã e da profissionalização na área ambiental. Neste contexto, a construção de instrumentos, processos e metodologias que possam ser incorporadas ao currículo do ensino formal e não formal, são ferramentas importantes já contempladas nas linhas de ação e estratégias do Programa Nacional de Educação Ambiental ${ }^{4}$. Segundo Costa, Monteiro e Costa (2008), referindo-se à Conferência de Tbilisi, a resolução de problemas ambientais é recomendada como estratégia metodológica para ações locais, a fim de estabelecer vínculos entre os processos educativos e a realidade cotidiana dos educandos ${ }^{5}$.

Por outro lado, a Iniciação Científica na escola, na maioria das vezes se resume à transmissão de conceitos teóricos sobre ciências, deixando-se em segundo ou nenhum plano o processo de investigação, que é a sua verdadeira natureza. Segundo Laranjeiras (2010), o ensino de Ciências na escola tem abdicado das Ciências, tornando-as ausentes de seu contexto, muitas vezes negando-as ou substituindo a experimentação em sua integridade epistemológica por atividades práticas ${ }^{6}$.

Sasseron e Carvalho (2011) elegem três eixos estruturantes da Alfabetização Científica: compreensão básica de termos, conhecimentos e conceitos científicos fundamentais; compreensão da natureza das Ciências e dos fatores éticos e políticos que circundam sua prática; e entendimento das relações existentes entre Ciência, Tecnologia, Sociedade e meio ambiente ${ }^{7}$. As autoras defendem que propostas didáticas que respeitem esses três eixos, devem ser capazes de promover a Iniciação Científica, pois se tem a oportunidade de trabalhar de forma integrada os problemas envolvendo a Sociedade e o ambiente. Nessa abordagem a alfabetização científica está diretamente ligada à pesquisa, pois segundo Demo (2006), dialogar com a realidade talvez seja a definição mais apropriada de pesquisa, pois saber dialogar de modo crítico e criativo faz da pesquisa condição de vida, progresso e cidadania. Como resultado o estudante levará para a sua vida o que cria por si mesmo e somente isso tem condições de fazer parte da sua atitude ${ }^{8}$.

O tema água como tema motivador para a Alfabetização Científica e para a Educação Ambiental torna-se um importante instrumento para fazer frente aos problemas relaciona- 
dos à escassez por quantidade e por qualidade, sendo este um elemento essencial à vida e um recurso de base socioeconômica fundamental à estruturação das Sociedades humanas e preservação da vida em suas mais diversas manifestações.

A legislação brasileira sobre recursos hídricos é um modelo ambicioso de gestão, prevendo que as decisões sobre seus usos em todo o País sejam tomadas pelos Comitês de Bacias Hidrográficas, que são constituídos por representantes da Sociedade Civil, do Estado e dos Municípios $^{9}$. Porém, a legislação aplicada de forma isolada não será capaz de assegurar o uso sustentável desse recurso natural, muito menos garantir que toda a população tenha acesso irrestrito a esse recurso considerado de domínio público. Neste sentido, além das disposições legais devem-se somar ações individuais e/ou ações coletivas que visem à conscientização das pessoas de maneira formal e/ou informal, quer seja na busca da conservação do bom estado dos recursos hídricos locais para as presentes e as futuras gerações, quer seja pela preservação do ambiente natural de forma perene. Sendo assim, a mobilização social e a Educação Ambiental são ferramentas importantes para que se alcancem as metas do sistema de gestão de recursos hídricos. Preparar as gerações futuras para o enfrentamento das dificuldades relacionadas à escassez de recursos hídricos seja por quantidade ou por qualidade é um dos desafios à Sociedade moderna, uma vez que trata-se do recurso essencial à própria sobrevivência por sua natureza integradora e unificadora das relações ecossistêmicas.

Neste contexto, o presente trabalho objetivou avaliar a efetividade da Educação Ambiental para o desenvolvimento de habilidades científicas em estudantes dos anos finais do Ensino Fundamental de uma escola pública, utilizando como tema motivador os recursos hídricos. Utilizando-se de pressupostos de Educação Ambiental, por meio da qual é possível atingir uma camada representativa da Sociedade, objetivou-se ainda a formação de multiplicadores ambientais. Para o desenvolvimento de tais habilidades nos participantes da pesquisa, o assunto recursos hídricos foi eleito como tema motivador, uma vez que consiste em um dos elementos naturais há muito impactado pelas atividades humanas.

\section{Desenvolvimento}

Neste estudo objetivou-se avaliar a efetividade da Educação Ambiental para o desenvolvimento de habilidades científicas em estudantes dos anos finais do Ensino Fundamental de uma escola pública, localizada na Microbacia do Arroio Pena Branca no Município de Caxias do Sul - RS, utilizando como tema motivador os recursos hídricos. A metodologia qualitativa participante foi escolhida para o desenvolvimento do trabalho e, como estratégias para coleta de dados, utilizou-se o questionário e o grupo focal.

\subsection{Atividades realizadas com os participantes}

As atividades realizadas com seis participantes foram orientadas e mediadas diretamente por dois professores colaboradores da Escola Municipal de Ensino Fundamental (EMEF) Italo João Balen, localizada no Município de Caxias do Sul - RS. Para a execução e aporte teórico dos conceitos necessários, utilizou-se de consulta a especialistas e especialidades da Universidade de Caxias do Sul. O método de aprendizagem ativa utilizado foi o Educar pela Pesquisa que consiste em estimular o estudante à curiosidade pelo desconhecido, incitá-lo a procurar respostas, a ter iniciativa, a compreender e iniciar a elaboração de suas próprias ideias, sendo o professor orientador do trabalho conjunto de forma coletiva e individual ${ }^{10}$. $\mathrm{O}$ Quadro 1 e o Quadro 2 resumem as atividades realizadas com os participantes na referida escola e no Arroio Pena Branca, no Município de Caxias do Sul - RS, no período de dezembro de 2014 à dezembro de 2015. 
Quadro 1. Atividades de ensino desenvolvidas e respectivos objetivos.

\begin{tabular}{|c|c|}
\hline Atividade & Objetivo \\
\hline $\begin{array}{l}\text { Atividade de campo no Arroio Pena } \\
\text { Branca, incluindo observação in loco e } \\
\text { registro fotográfico. }\end{array}$ & $\begin{array}{l}\text { Conscientizar quanto aos impactos am- } \\
\text { bientais sobre os recursos hídricos. }\end{array}$ \\
\hline $\begin{array}{l}\text { Aprendizagem de conceitos sobre os re- } \\
\text { cursos hídricos através de leitura, com- } \\
\text { preensão e resolução de exercícios do } \\
\text { Guia Rede Nacional de Capacitação e } \\
\text { Extensão Tecnológica em Saneamento } \\
\text { Ambiental }^{11} \text {. }\end{array}$ & $\begin{array}{l}\text { Fundamentar teoricamente os partici- } \\
\text { pantes sobre recursos hídricos. }\end{array}$ \\
\hline $\begin{array}{l}\text { Reuniões com os professores e direção } \\
\text { da escola. Atividade de campo com } \\
\text { os professores e direção. } 1^{\text {a }} \text { Feira de } \\
\text { Ciências da EMEF Italo João Ba- } \\
\text { len.Palestras aos demais estudantes da } \\
\text { escola. }\end{array}$ & $\begin{array}{l}\text { Despertar o interesse da comunidade es- } \\
\text { colar pelas questões ambientais. }\end{array}$ \\
\hline
\end{tabular}

Quadro 2. Atividades de pesquisa desenvolvidas e respectivos objetivos.

\begin{tabular}{|l|l|}
\hline \multicolumn{1}{|c|}{ Atividade } & \multicolumn{1}{|c|}{ Objetivo } \\
\hline $\begin{array}{l}\text { Coleta de água no Arroio Pena Branca } \\
\text { e medição de alguns parâmetros físicos } \\
\text { e químicos em campo.Análise de resul- } \\
\text { tados da qualidade da água medida em } \\
\text { campo e interpretação de laudos labo- } \\
\text { ratoriais. }\end{array}$ & $\begin{array}{l}\text { Desenvolver habilidades para a coleta } \\
\text { ze amostras de água em campo, utili- } \\
\text { to.Analisar a qualidade da água através } \\
\text { de parâmetros físicos e químicos. }\end{array}$ \\
\hline $\begin{array}{l}\text { Determinação do IQA do Arroio Pena } \\
\text { Branca. }\end{array}$ & $\begin{array}{l}\text { Conhecer o método de cálculo do Índice } \\
\text { de Qualidade da Água (IQA) através de } \\
\text { ferramenta do Sistema de Informações } \\
\text { Ambientais (SIA). }\end{array}$ \\
\hline $\begin{array}{l}\text { Enquadramento do Arroio Pena Bran- } \\
\text { ca na Resolução no 357 do CONAMA } \\
\text { através do jogo "Aquadradoce". }\end{array}$ & $\begin{array}{l}\text { Conhecer a resolução no 357 do Con- } \\
\text { selho Nacional do Meio Ambiente (CO- } \\
\text { NAMA) e compreender os critérios de } \\
\text { classificação das águas doces. }\end{array}$ \\
\hline $\begin{array}{l}\text { Biomonitoramento da qualidade da } \\
\text { água do Arroio Pena Branca. Coleta, } \\
\text { triagem e identificação de macroinverte- } \\
\text { brados aquáticos do Arroio Pena Bran- } \\
\text { ca. Montagem de coleção de macroin- } \\
\text { vertebrados coletados. }\end{array}$ & $\begin{array}{l}\text { Desenvolver habilidades para a coleta } \\
\text { de macroinvertebrados aquáticos. Ana- } \\
\text { lisar quali-quantitativamente a fauna de } \\
\text { macroinvertebrados em cursos d'água. } \\
\text { Analisar a qualidade da água através de } \\
\text { parâmetro biológico. }\end{array}$ \\
$\begin{array}{l}\text { Montagem e monitoramento de um na } \\
\text { Montagem de terrários. }\end{array}$ & $\begin{array}{l}\text { Realizar analogias entre ecossistema na- } \\
\text { tural e ecossistema artificial. }\end{array}$ \\
\hline
\end{tabular}


Elaboração de resumos, relatórios e pôsteres para apresentação, divulgação e publicação dos resultados em eventos técnico-científicos e pedagógicos.
Desenvolver a competência para produção, apresentação, divulgação e publicação de trabalhos científicos.

\subsection{Avaliação do processo realizado}

\subsubsection{Comparação dos conhecimentos prévios e adquiridos sobre recursos hídricos}

Após o desenvolvimento da primeira atividade de ensino, a etapa de conscientização, os seis estudantes responderam um questionário individual inicial, a fim de verificar os conceitos já construídos sobre o tema recursos hídricos no decorrer de sua formação, bem como verificar suas percepções no primeiro contato com o Arroio Pena Branca. Este questionário foi aplicado novamente, quando da finalização do trabalho, a fim de comparar os conhecimentos prévios dos estudantes com os conhecimentos no final da experiência de pesquisa.

\subsubsection{Grupo focal}

Quando do encerramento do trabalho, após um ano de desenvolvimento das atividades, os seis estudantes participantes foram convidados a participar de entrevista, o grupo focal. O seu propósito foi observar como os participantes interpretaram a realidade, seus conhecimentos e experiências. Puderam se manifestar oralmente evitando falas concomitantes e interrupções. Os participantes foram questionados sobre suas vivências durante a execução do trabalho, que mudanças internas resultaram e a efetividade da Educação Ambiental no desenvolvimento de habilidades científicas. Esta reunião de, aproximadamente, duas horas, foi completamente flexível e não estruturada, na ótica dos observados, dando margem a discussão do assunto, sendo conduzida por um observador e um moderador. Segundo Dias (2000), o moderador, atua no grupo de maneira a redirecionar a discussão, caso haja dispersão ou desvio do tema pesquisado, sem, no entanto, interromper bruscamente a discussão ${ }^{13}$. O observador, por sua vez, faz a observação e o registro minucioso de todos os acontecimentos, inclusive os não verbais que apareceram na comunicação ${ }^{14}$. Estas conversas foram registradas por meio de gravação de áudio/vídeo/digital, utilizando-se, para isso, uma filmadora com microfone adaptado para gravação digital, com digitalização das falas para compor a descrição escrita dos relatos feitos. Esta foi analisada, a fim de avaliar a efetividade da Educação Ambiental no desenvolvimento de habilidades científicas na formação dos estudantes participantes.

\section{Resultados e Discussão}

O questionário individual aplicado aos estudantes no início e final do trabalho revelou informações importantes a respeito dos conhecimentos construídos pelos mesmos ao final da experiência de pesquisa. Os resultados estão apresentados no Quadro 3 contendo o assunto questionado, sendo escolhida a resposta de um dos seis participantes antes e depois da vivência. Os participantes foram numerados de 1 a 6 e organizados por ano em curso no Ensino Fundamental em 2015: participantes 1 e 2 eram estudantes do $9^{\circ}$ ano; participantes 
ISSN: 2358-1271. Int. J. of Alive Eng. Educ. (IJAEEdu). (Online). Goiânia, v. 4, n. 1, p. 69-82, jan./june 2017.75

3 e 4 eram estudantes do $8^{\circ}$ ano e participantes 5 e 6 eram estudantes do $7^{\circ}$ ano.

Quadro 3. Questões sobre o tema recursos hídricos e resposta de um dos seis participantes, antes e depois da pesquisa.

\begin{tabular}{|c|c|c|}
\hline & ANTES & DEPOIS \\
\hline $\begin{array}{l}\text { O rio como ecossistema: } \\
\text { Como você vê o rio hoje? }\end{array}$ & $\begin{array}{l}\text { "Um rio com péssimas con- } \\
\text { dições e cheiro ruim de es- } \\
\text { goto, com muitos macroin- } \\
\text { vertebrados que fazem mal } \\
\text { a água, sem pássaros e sem } \\
\text { peixes, com água suja e mui- } \\
\text { to lixo ao redor e dentro do } \\
\text { rio." }\end{array}$ & $\begin{array}{l}\text { "Um local delicadamente li- } \\
\text { gado com a natureza, de mo- } \\
\text { do que qualquer aconteci- } \\
\text { mento prejudicial à natureza } \\
\text { terá total impacto nos rios." }\end{array}$ \\
\hline $\begin{array}{l}\text { A substância água: Como } \\
\text { você definiria a substância } \\
\text { água? }\end{array}$ & $\begin{array}{l}\text { "Uma substância muito usa- } \\
\text { da tanto pelo homem quan- } \\
\text { to pelos animais e a nature- } \\
\text { za, meio fundamental para a } \\
\text { vida e uma das substâncias } \\
\text { que compõe nosso corpo." }\end{array}$ & $\begin{array}{l}\text { "Um patrimônio usado pe- } \\
\text { la humanidade tanto para } \\
\text { lazer quanto para saúde e } \\
\text { principalmente para a sobre- } \\
\text { vivência e que está em mino- } \\
\text { ria a sua parte apropriada às } \\
\text { necessidades vitais." }\end{array}$ \\
\hline $\begin{array}{l}\text { Impactos das ações hu- } \\
\text { manas sobre a água/rios: } \\
\text { Que impactos você perce- } \\
\text { beu/percebe sobre os rios, } \\
\text { resultantes das nossas ati- } \\
\text { vidades do dia a dia? }\end{array}$ & $\begin{array}{l}\text { "O descarte não consciente } \\
\text { dos esgotos ou até mesmo } \\
\text { resíduos poluentes." }\end{array}$ & $\begin{array}{l}\text { "Diversos impactos como } \\
\text { por exemplo: efluentes } \\
\text { domésticos e industriais, } \\
\text { despejo de lixo, industriali- } \\
\text { zação, o aquecimento global } \\
\text { que também atinge os rios, } \\
\text { etc." }\end{array}$ \\
\hline $\begin{array}{l}\text { A bacia hidrográfica: Você } \\
\text { sabe o que é bacia hi- } \\
\text { drográfica? }\end{array}$ & "Não.' & $\begin{array}{l}\text { "Bacia hidrográfica é o con- } \\
\text { junto de rios, lagos, etc..." }\end{array}$ \\
\hline $\begin{array}{l}\text { Saneamento ambien- } \\
\text { tal: Existem medi- } \\
\text { das/obras/estruturas de } \\
\text { saneamento instaladas no } \\
\text { rio que visitamos? Quais? }\end{array}$ & "Não." & $\begin{array}{l}\text { "Sim. Uma estação de trata- } \\
\text { mento de esgoto." }\end{array}$ \\
\hline $\begin{array}{l}\text { Ciclo hidrológico/ciclo da } \\
\text { água: Se não chover, o rio } \\
\text { vai estar lá? }\end{array}$ & $\begin{array}{l}\text { "Não porque a água tem que } \\
\text { encher o rio." }\end{array}$ & $\begin{array}{l}\text { "Não porque o rio não enche } \\
\text { sozinho precisa chover para } \\
\text { o rio encher." }\end{array}$ \\
\hline
\end{tabular}

Com base nas respostas apresentadas, observa-se que antes da vivência de pesquisa os participantes revelam um senso comum, resultado das observações imediatas feitas com base nas características físicas quando do contato com o Arroio Pena Branca e nos conceitos aprendidos na escola resultado de sua formação básica. Depois da vivência os participantes já conseguiram ir além das características sensoriais, estabelecendo relações entre o arroio e o ecossistema, percebendo-o como parte do todo, como um local que requer cuidados e "delicadamente ligado com a natureza". Sobre assuntos relacionados à qualidade da água e métodos de monitoramento de corpos hídricos, os participantes demonstram apropriação de 
conceitos e conhecimentos específicos após a experiência de pesquisa (conforme o Quadro $4)$.

Quadro 4. Qualidade da água: Como podemos avaliar a qualidade da água em campo, no laboratório e a partir de organismos presentes no meio aquático?.

\begin{tabular}{|c|c|c|}
\hline & ANTES & DEPOIS \\
\hline \multirow{3}{*}{2} & $\begin{array}{l}\text { "Em campo pelo cheiro e aspecto } \\
\text { físico." }\end{array}$ & $\begin{array}{l}\text { "Em campo através de aspectos físicos } \\
\text { como odor, cor, sabor e por parâmetros } \\
\text { físicos e químicos: OD, ORP, DBO, } \\
D Q O \text {, turbidez, condutividade elétrica } \\
\text { e outros." }\end{array}$ \\
\hline & $\begin{array}{l}\text { "No laboratório com meios mais detal- } \\
\text { hados." }\end{array}$ & $\begin{array}{l}\text { "No laboratório calculando os índices } \\
\text { avaliados - parâmetros físicos e } \\
\text { químicos - encontrados em campo." }\end{array}$ \\
\hline & $\begin{array}{l}\text { "Pelas suas capacidades de sobre- } \\
\text { vivência e adaptação." }\end{array}$ & $\begin{array}{l}\text { "Comparando famílias, ordens e } \\
\text { espécies de macroinvertebrados que se } \\
\text { encontram na água." }\end{array}$ \\
\hline
\end{tabular}

Durante o trabalho foram realizadas atividades de biomonitoramento no Arroio Pena Branca, utilizando-se macroinvertebrados aquáticos. Antes da experiência de pesquisa, os macroinvertebrados aquáticos eram um assunto totalmente desconhecido pelos participantes, tornando-se uma das atividades mais apreciadas pelos mesmos. Após as vivências, todos os participantes passaram a reconhecer os macroinvertebrados como bioindicadores da qualidade da água, atribuindo-lhes grande importância para a natureza, conforme descrito no Quadro 5.

Quadro 5. Macroinvertebrados aquáticos: Você conhece os macroinvertebrados aquáticos? O que são?.

\begin{tabular}{|c|c|c|}
\hline & ANTES & DEPOIS \\
\hline 1 & $\begin{array}{l}\text { "Não. Pequenos animais invertebrados, } \\
\text { que indicam se a água está boa ou } \\
\text { ruim." }\end{array}$ & $\begin{array}{l}\text { "Sim. Bioindicadores da qualidade da } \\
\text { água, que tem grande importância na } \\
\text { natureza." }\end{array}$ \\
\hline 2 & $\begin{array}{l}\text { "Não. São muito importantes para a de- } \\
\text { finição do estado da água, isto é, sua } \\
\text { qualidade." }\end{array}$ & $\begin{array}{l}\text { "Sim. São seres que contribuem para a } \\
\text { avaliação da qualidade da água de um } \\
\text { determinado lugar." }\end{array}$ \\
\hline 3 & $\begin{array}{l}\text { "Não. Seres fundamentais para nos aju- } \\
\text { dar a descobrir a qualidade da água." }\end{array}$ & $\begin{array}{l}\text { "Sim. Seres que com análise apropriada } \\
\text { nos mostram a qualidade da água dos } \\
\text { rios." }\end{array}$ \\
\hline 4 & $\begin{array}{l}\text { "Não. São seres que merecem serem es- } \\
\text { tudados." }\end{array}$ & $\begin{array}{l}\text { "Sim. São animais que nos dizem como } \\
\text { está a qualidade da água." }\end{array}$ \\
\hline 5 & $\begin{array}{l}\text { "Não. Como bichos da água que aju- } \\
\text { dam a cuidar." }\end{array}$ & $\begin{array}{l}\text { "Sim. Eles são bioindicadores da água } \\
\text { então dependendo como a água está, } \\
\text { pra mim eles são bem importantes." }\end{array}$ \\
\hline 6 & $\begin{array}{l}\text { "Não. Ainda acho eles nojentos mais } \\
\text { achei legal ver eles perto com a lupa." }\end{array}$ & $\begin{array}{l}\text { "Sim. Hoje eu vejo o quanto eles são } \\
\text { importantes para a natureza, pois indi- } \\
\text { cam a qualidade da água." }\end{array}$ \\
\hline
\end{tabular}


Os resultados apontam sobre a possibilidade de estudantes do Ensino Fundamental realizarem o monitoramento da qualidade da água em regiões urbanas, tanto com a análise da qualidade da água utilizando equipamentos de monitoramento e métodos laboratoriais, quanto através da análise quali-quantitativa dos macroinvertebrados encontrados na água, desenvolvendo habilidades científicas. Com os resultados obtidos no trabalho, pode-se afirmar que os estudantes de Ensino Fundamental compreenderam que organismos aquáticos, como macroinvertebrados, podem auxiliar na identificação das condições de qualidade da água de um recurso hídrico, além de desenvolver a habilidade de classificar as diferentes famílias de macroinvertebrados e relacioná-las à qualidade da água que elas indicam. Os participantes da pesquisa puderam compreender os fatores que interferem na sobrevivência de organismos presentes nos rios, bem como a importância da preservação do meio ambiente. Assim, compreenderam os fatores e de que maneira contribuíram para a poluição deste arroio.

Com a montagem do aquário, o grupo passou a perceber as semelhanças e diferenças entre o aquário e o arroio, comparando e discutindo a visão de cada um com relação a esses meios, desenvolvendo uma postura diferente com relação aos ecossistemas, tornandose ativos nos processos de preservação ambiental. A analogia entre o aquário e o arroio tornou-se uma estratégia de ensino para aprendizagem significativa dos estudantes, pois facilitou a compreensão de alguns acontecimentos recorrentes aos dois meios. Durante o período da prática da atividade envolvendo o aquário observou-se a motivação e o interesse, não apenas dos estudantes diretamente envolvidos no projeto, mas de toda a comunidade escolar, inclusive visitantes da escola, despertando a sensibilização ambiental e a percepção da importância da preservação dos ecossistemas análogos ao aquário.

Como questionamento final, os participantes relataram suas expectativas com variados níveis de proposição, tanto no início quanto no final do trabalho. Um dos sujeitos tinha como expectativa aprender um pouco mais sobre Ciências, outro já evidenciava afinidade com esta área do conhecimento, pretendendo participar do trabalho para poder se especializar futuramente. Para todos os participantes o trabalho foi além das expectativas iniciais, pois puderam interagir e expandir seus conhecimentos na área ambiental, sendo que para alguns essa afinidade se revelou no desejo de dar continuidade enquanto formação futura.

Esses resultados tornam-se evidentes durante a realização da entrevista no grupo focal, quando buscamos levantar os fatos com os quais os sujeitos despertaram para a vocação científica e para a conscientização ambiental durante a participação no trabalho. De acordo com os relatos dos estudantes, as atividades envolvendo o tema recursos hídricos contribuíram para seu autoconhecimento e superação de dificuldades, conforme relatos dos sujeitos 2, 3 e 5 apresentados no Quadro 6.

Quadro 6. Estas vivências foram positivas ou negativas para o seu despertar à vocação científica?.

\begin{tabular}{|c|l|}
\hline 2 & $\begin{array}{l}\text { "De modo geral serviu de aprendizado. O contato com especialistas é uma } \\
\text { grande experiência... A coleta a campo foi o mais diferencial do projeto. Saldo } \\
\text { positivo." }\end{array}$ \\
\hline 3 & $\begin{array}{l}\text { "Positivo e negativo. O aprendizado é na área que eu quero estudar no futuro, } \\
\text { me acrescentaram muito, a percepção humana no meio ambiente." }\end{array}$ \\
\hline 5 & $\begin{array}{l}\text { "Todas positivas, pois aprendemos tudo o que não sabíamos que existia. Não } \\
\text { sabia que existiam os macros." }\end{array}$ \\
\hline
\end{tabular}


O despertar para a vocação científica ocorreu no decorrer do trabalho, mas principalmente nas atividades relacionadas aos macroinvertebrados e ao aquário, afirmam os sujeitos 1, 4 e 6 apresentados no Quadro 7.

Quadro 7. Você despertou para a vocação científica ao longo do projeto? Se sim, como isso aconteceu?.

\begin{tabular}{|c|l|}
\hline 1 & $\begin{array}{l}\text { "No caso despertou para mim porque gosto muito de química: o aquário, pois } \\
\text { é algo que eu gosto muito de fazer. Agora gosto mais de química, pois vi na } \\
\text { prática o que estudava na teoria." }\end{array}$ \\
\hline 4 & $\begin{array}{l}\text { "Para mim foi na parte em que começamos a triar os macros e consegui iden- } \\
\text { tificar eles. Parece que ligou uma luz na minha cabeça, é isto que eu gosto e } \\
\text { é aquilo que eu quero. As coletas são legais, mas quando vim aqui e aprendi } \\
\text { sobre os macros foi diferente. É disso que eu gosto." }\end{array}$ \\
\hline 6 & $\begin{array}{l}\text { "Na verdade sim, todo o projeto despertou um pouquinho, pois eu não gos- } \\
\text { tava de Ciências. Mas depois eu comecei a entender mais. Não teve nenhuma } \\
\text { atividade específica. Tudo despertou um pouquinho." }\end{array}$ \\
\hline
\end{tabular}

A mudança na relação dos sujeitos com a natureza, antes e depois do projeto, também fica evidente nos seus depoimentos do grupo focal (conforme mostra o Quadro 8).

Quadro 8 - A sua relação com a natureza antes e depois do projeto.

\begin{tabular}{|c|c|}
\hline 1 & $\begin{array}{l}\text { "Eu acho que antes do projeto, eu pensava que a natureza era onde os animais } \\
\text { viviam. Agora eu vejo que tudo está interligado. Se eu mexer em alguma coisa } \\
\text { na natureza vai ter consequências ruins. Tem que cuidar da natureza e não } \\
\text { fazer mal a ela, pois vai voltar para a gente." }\end{array}$ \\
\hline 2 & $\begin{array}{l}\text { "A minha parte, antes do projeto, claro que dentro da escola a gente aprende, } \\
\text { já tinha a percepção que a poluição era errada e trazia consequências. Pu- } \\
\text { de aprofundar meu conhecimento. Os macros foram muito interessantes. As } \\
\text { nossas ações têm consequências ao ambiente dos macros, e com ele podemos } \\
\text { perceber qual a condição do meio. Resíduos domésticos gerados e mal descar- } \\
\text { tados, industriais, que parecem mínimos geram graves consequências." }\end{array}$ \\
\hline 3 & $\begin{array}{l}\text { "Antes do projeto eu era fresca no quesito natureza: não chegava perto disso, } \\
\text { não gostava daquilo. Depois do projeto, claro com acidentes, foi uma coisa que } \\
\text { eu aprendi a perder meus medos e eu consegui chegar mais perto da natureza, } \\
\text { eu consegui prestar mais atenção, me comunicar mais com o meio ambiente. } \\
\text { Depois das vivencias que eu tive, foi uma mudança bem radical." }\end{array}$ \\
\hline 4 & $\begin{array}{l}\text { "Antes do projeto eu já tinha contato com a natureza, mas também tinha } \\
\text { medo. Tinha noção da poluição, mas só o que aprendíamos na escola. Depois do } \\
\text { projeto, como estivemos neste meio, eu percebi que não importa se a poluição } \\
\text { é pequena ou grande, vai alterar em alguma coisa. A minha percepção mudou } \\
\text { bastante. Agora me controlo mais, eu não estava nem aí, mas agora eu já tenho } \\
\text { uma noção maior das minhas ações." }\end{array}$ \\
\hline 5 & $\begin{array}{l}\text { "Não era muito apegada e não me importava muito. Pude perceber as } \\
\text { entre poluição e a qualidade do rio." }\end{array}$ \\
\hline
\end{tabular}




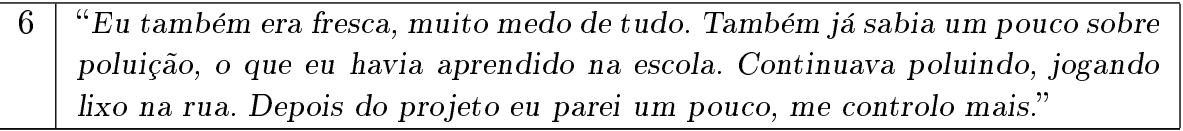

A necessidade do desenvolvimento de uma educação voltada para a discussão de questões relacionadas à conservação e manejo dos recursos naturais é hoje realidade ${ }^{15}$. Porém, uma das maiores dificuldades dos professores tem sido a escassez de recursos didáticos que permitam a transmissão do conteúdo técnico-científico em Ecologia utilizando uma linguagem acessível e de fácil compreensão ${ }^{16}$. Como a meta da gestão ambiental é desenvolver e aplicar métodos, tanto em sistemas de produção como em seus sistemas naturais, almejando uma relação sustentável entre o homem e o meio ambiente, observa-se que a participação nas atividades de pesquisa contribuiu nessa busca, principalmente no sentido de aproximar o estudante ao seu entorno, seu bairro, sua cidade, tornando-o consciente do meio natural existente no seu meio construído, no ecossistema urbano chamado cidade. Além disso, ao sensibilizá-lo para que se sinta parte deste meio natural, poderá agir como cuidador deste, conservando os recursos naturais no pleno exercício da sua cidadania, tornando-se um multiplicador ambiental auxiliando na busca pela sustentabilidade.

\section{Conclusões}

No decorrer deste trabalho, os estudantes estabeleceram inter-relações com os recursos naturais e os seres vivos, valorizando o meio ambiente. Também compreenderam melhor alguns termos e procedimentos usados no meio científico. Ao interagir nas atividades propostas puderam desenvolver uma postura frente às relações entre os seres humanos e os seres vivos relacionando-se de maneira diferente com os ecossistemas, podendo tornar-se ativo nos seus processos de preservação. Estas habilidades foram desenvolvidas ao longo do período de execução, conscientizando-os gradativamente quanto aos impactos ambientais sobre os recursos hídricos. Os registros e vivências que tiveram, tornaram evidentes as causas da poluição no ambiente natural e o quanto o conhecimento e a iniciação científica são importantes para que se possa desempenhar um papel proativo na gestão ambiental, planejando mudanças próximas ou futuras que visam a não poluição do meio aquático e como poderiam atuar no futuro enquanto profissionais. Foi possível perceber ainda o despertar da compreensão para os efeitos das ações humanas no meio ambiente e refletir sobre possíveis mudanças e métodos que podem ser utilizados para a preservação e conservação dos recursos naturais e em particular a água.

A possibilidade da Iniciação Científica no Ensino Fundamental favoreceu para que estes estudantes pudessem compreender desde cedo as consequências de algumas ações humanas sobre o ambiente, a importância da preservação e as consequências da falta de cuidado com os recursos hídricos, compreendendo ainda que ações de minimização, reparo, ou mesmo a perspectiva de evitar estes impactos requer profissionais com formações específicas que lhe permitam realizar intervenções neste sentido.

O envolvimento dos alunos de Ensino Fundamental nas atividades de pesquisa demonstrouse uma importante ferramenta para a compreensão das metodologias científicas e sua aplicabilidade em atividades de Educação Ambiental e para a formação profissional futura. Além disso, a construção de instrumentos, processos e metodologias que possam ser incorporadas ao currículo do ensino formal e não formal, são ferramentas importantes na busca de atitudes de respeito ao meio ambiente. 


\section{Agradecimentos}

Este trabalho foi realizado em uma parceria entre a Universidade de Caxias do Sul (UCS), através do Instituto de Saneamento Ambiental (ISAM) e a Escola Municipal de Ensino Fundamental Italo João Balen, do Município de Caxias do Sul - RS, sendo que os recursos foram oriundos da Fundação Estadual de Amparo à Pesquisa (FAPERGS) e da Coordenação de Aperfeiçoamento de Pessoal de Nível Superior (CAPES).

\section{Referências}

1. SECCO, M. F. F. V. O Conceito de Bacia Hidrográfica como Instrumento de Educação Ambiental: uma experiência na Escola Bosque de Belém/PA. Departamento de Museologia (DMU)/Serviço de Educação e Extensão Cultural (SEC)/Museu Paraense Emílio Goeldi (MPEG). 1998.

2. CALLISTO, M.; FRANÇA, J. Bioindicadores de Qualidade de Água: transmissão de metodologias para o ensino fundamental e médio. Em:ENCONTRO DE EXTENSÃO DA UNIVERSIDADE FEDERAL DE MINAS GERAIS, $7^{\circ}$, 2004, Belo Horizonte. Anais.... Belo Horizonte: UFMG, 2004 . Disponível em: <https://www.ufmg.br/congrext/Meio/Meio6.pdf >. Acessado em: 31 ago. 2017

3. BRASIL. Lei Federal $\mathrm{n}^{\circ} 9.795 / 99$, de 27 de abril de 1999 . Institui a Política Nacional de Educação Ambiental e dá outras providências. 1999. Disponível em: <http: //www.cetesb.sp.gov.br>. Acesso em: nov. 2014 e jul. 2015.

4. Programa Nacional de Educação Ambiental. ProNEA. Programa Nacional de Educação Ambiental. Ministério do Meio Ambiente. 5. ed. Brasília. 2005a.

5. COSTA, M. de F. B.; MONTEIRO, S. C. F.; COSTA, M. A. F. Projeto de Educação Ambiental no Ensino Fundamental: bases para práticas pedagógicas. Revista eletrônica Mestrado em Educação Ambiental, Rio Grande, v. 21, jul./dez. 2008. Disponível em: $<$ https://www.seer.furg.br/remea $>$. Acessado em: 31 ago. 2017.

6. Laranjeiras, C. C. Um ensino de ciências sem ciências: um simulacro de educação científica. Artigo extraído do Jornal da Ciência por e-mail no. 3980, de 31 de Março de 2010. Disponível em: <http://www.jornaldaciencia.org.br/Detalhe.jsp?id=69992>. Acesso em: out. 2015.

7. SASSERON, L. H.; CARVALHO, A. M. P. Alfabetização Científica: uma revisão bibliográfica. Faculdade de Educação. USP. In: Investigações em Ensino de Ciências, v. 16, n. 1, pp. 59-77, 2011.

8. P. Demo. Pesquisa: princípio científico educativo. São Paulo: Cortez, 2006.

9. BRASIL. Lei Federal n ${ }^{\circ}$ 9.433/97, de 08 de janeiro de 1997. Institui a Política Nacional dos Recursos Hídricos e dá outras providências. 1997. Disponível em: <http: //www.cetesb.sp.gov.br >. Acesso em: nov. 2014 e jul. 2015.

10. P. Demo. Educar pela pesquisa. Campinas: Editora Autores Associados, 1996.

11. ReCESA - Rede Nacional de Capacitação e Extensão Tecnológica em Saneamento Ambiental. Qualidade da Água: padrões de potabilidade e controle da poluição. Guia do profissional em treinamento: Esgotamento Sanitário, Brasília, Nível 2. Secretaria Nacional de Saneamento Ambiental - Ministério das Cidades. 2013. Disponível em: $<$ http://nucase.desa.ufmg.br/wpcontent/uploads/2013/07/ES-QACP.2.pdf > . Acessado em: 31 ago. 2017.

12. BRASIL. CONAMA. Resolução $\mathrm{n}^{\circ}$ 357, de 17 de março de 2005. 2005b. Disponível em: $<$ http://www.mma.gov.br/port/conama/res/res05/res35705.pdf $>$. Acesso em: 10 maio de 2015.

13. DIAS, C. A. Grupo focal: técnica de coleta de dados em pesquisas qualitativas. Tese de Mestrado em Ciência da Informação. Universidade de Brasília. DF. 2000.

14. LOURINHO, L. A. Educação na cidade de Fortaleza: diagnóstico e realidade. Prefeitura Municipal de Fortaleza. CE. 2007. 
ISSN: 2358-1271. Int. J. of Alive Eng. Educ. (IJAEEdu). (Online). Goiânia, v. 4, n. 1, p. 69-82, jan./june 2017.

15. PALHARES, K.; MAYRINK, N.; MORENO, P.; GOULART, M.; MORETTI, M.; FERREIRA, W.; DINIZ, A. P.; RODRIGUES, L.; CALLISTO, M. Bioindicadores de Qualidade de Água: a educação ambiental como uma ferramenta de união UFMG - Escolas. In: SIMPÓSIO DE ECOSSISTEMAS BRASILEIROS, V., 2000, Vitória. Anais... São Paulo: ACIESP, 2000. V. 1. p. $182-189$

16. MACHADO, J. F. Fazendo a educação ambiental na escola. Programa de Educação Ambiental na Bacia do Rio Piracicaba: Curso de formação de Professores na área ambiental; Guerra e Barbosa. UFMG/ICB:BH. 1996. 
